\title{
Editorial
}

\section{Radiation Exposure to Staff Using PET/CT Facility}

\author{
Taalab, Kh; and Mohsen, $\mathrm{Z}$
}

Department of Nuclear Medicine, International Medical Center; Cairo, Egypt

\begin{abstract}
:
Positron emission tomography (PET) combined with computed tomography (CT) has been playing key role in important clinical decision-making in many areas ever since its inception in the field of medical imaging. Most of the hospitals are enthusiastic for including PET/CT in their imaging services because of its increasing application particularly in oncology. However, the occupational workers are apprehensive about the risk of higher radiation exposure in a $\mathrm{PET} / \mathrm{CT}$ facility even more than that in conventional nuclear medicine Gamma camera. There is a need therefore to make the staff aware of the radiation doses they may likely get while
\end{abstract} \begin{abstract}
working using this facility. We have estimated the radiation exposure to the physicians \& technologists working in our PET/CT facility based on the dose rate measurement with regularly calibrated pocket dosimeter and thermo-luminescent detector (TLD); for cumulative dose confirmation. The mean dose measured at the chest level per PET/CT procedure was $4 \mu \mathrm{Sv}$ and $4.75 \mu \mathrm{Sv}$ for the physicians and technologists respectively. The mean dose to the physicians per $\mathrm{MBq}$ of $18 \mathrm{~F}-\mathrm{FDG}$ injected was $10 \mathrm{nSv} / \mathrm{MBq}$ and $35 \mathrm{nSv} / \mathrm{MBq}$ at the chest and wrist levels respectively; whereas it was 12 and $25 \mathrm{nSv} / \mathrm{MBq}$ for technicians respectively.
\end{abstract}

Key words: Radiation dose, PET/CT, pocket dosimeter. 


\section{INTRODUCTION:}

Functional disorders always predate anatomical abnormalities; hence availability of both physiological and anatomical images of the patient on the same system provides the early detection and precise location of the lesion that is helpful to the physicians in image interpretation to a great extent.

Accordingly; multi-modality imaging technology like PET/CT has revolutionized and established the role of PET imaging as a diagnostic tool in many areas particularly in oncology ${ }^{(\mathbf{1})}$.

Due to newer developments in detector technology application of this imaging technology will continue to increase with higher patient throughput. The high patient throughput in $\mathrm{PET} / \mathrm{CT}$ may also raise concern as it may increase the radiation exposure to staff members.

The high specific gamma ray constant and penetrating 511-keV photons, result in a higher radiation exposure to staff if not adequately protected (2).

The $140-\mathrm{keV}$ photons from $99 \mathrm{mTc}$ have a half value layer of $0.28 \mathrm{~mm}$ of lead against $4.1 \mathrm{~mm}$ for $511-\mathrm{keV}$ photons under narrow beam geometry ${ }^{(3)}$.

The amount of lead required to suitably shield these high-energy emissions is therefore proportionately increased. The specific gamma-ray constant for $18 \mathrm{~F}$ is nearly six times greater than that for $99 \mathrm{mTc}^{(2,3)}$.

Radiation safety issues with a PET/ CT facility have therefore to be addressed adequately.

A large number of studies are available in the literature on the evaluation of radiation safety and dose received by staff performing imaging with conventional nuclear medicine tracers ${ }^{(4-8)}$.

Even though published data are available on exposure to staff working in a dedicated $\mathrm{PET} / \mathrm{CT}$ facility, there is no consensus between them on the estimated dose to $\operatorname{staff}^{(9-11)}$.

In this study we have estimated the average dose received by the physicians and technologists at the chest and wrist level while performing 18F-FDG injections; dose dispensing and administration and patient positioning during acquisitions respectively.

\section{MATERIALS AND METHODS:}

A prospective pilot study was carried out to estimate the average dose to the physicians and technologists during 18F-FDG PET/CT imaging of 125 adult patients in International Medical Center (IMC) in May 2013. The center has a dedicated PET/CT scanner, (Philips; TF).

For all PET/CT whole body imaging, first spiral CT is performed for the whole body by using a scout view with $30 \mathrm{~mA}$ and 130 $\mathrm{kVp}$, followed by a spiral CT scan with 50 $\mathrm{mA}$ and $130 \mathrm{kVp}$. This is followed by 3D PET acquisition with 4 min bed positions depending upon the true count rate from the patient. For whole body PET/CT imaging of adult patients, around $370 \mathrm{MBq}(10$ $\mathrm{mCi}$ ) of $18 \mathrm{~F}-\mathrm{FDG}$ was injected. The total acquisition time per whole body scan varies from 20 to $25 \mathrm{~min}$. On an average 12-15 patients are imaged in this scanner a day; for two day per week.

At any time two physicians and two technologists are posted in the facility for injections and PET/CT imaging of the patients respectively. 


\section{Dose measurements:}

Electronic pocket dosimeters (Siemens Medical Solutions Inc, USA), were used for dosimetry per PET/CT imaging procedure. The measurement range of the detector was from $0.1 \mu \mathrm{Sv}$ to $100 \mathrm{mSv}$, with an in-built beeper.

During the 1-month period of the study two TLD dosimeters were given to each physician and technologist to wear on the chest and wrist levels.

These dosimeters have silicon semiconductor detectors with an accuracy of $\pm 10 \%$, linearity within $\pm 10 \%$ and an energy response accuracy of $\pm 20 \%$ between $50 \mathrm{KeV}$ and $3 \mathrm{MeV}$.

The constancy of the dosimeters was checked against a $137 \mathrm{Cs}$ source before use. The dosimeters were worn at all times when the physicians and technologists are performing 18F-FDG injections and $\mathrm{PET} / \mathrm{CT}$ imaging respectively.

The radiation dose to physicians was recorded during the 18F-FDG injections whereas; the dose received by the technologists was measured while dose dispensing and performing PET/CT scans. The chest and wrist dose received by the staff were read directly from the dosimeters and recorded at the end of each working day, and the dosimeters were reset. The total activity administered by each of the physicians and the numbers of PET/CT scans performed by the technologists were recorded.

Instantaneous dose rates measurements:

The instantaneous dose rates were measured using a calibrated survey meter (Ludlum Measurements, Inc, USA) portable gamma ray survey meter.

Prior to injection, patients were prepared with intravenous cannula in their vein for dose administration to minimize the time of injection. The syringe loaded with $18 \mathrm{~F}$ FDG was quickly removed from the lead container and dose was injected to the patients. The exposure rates to the chest and wrist levels of physicians were measured during $18 \mathrm{~F}-\mathrm{FDG}$ injections to the patients.

The dose rates were also measured at $0,0.5$, 1.0 and $2.0 \mathrm{~m}$ distance from the anterior chest of each patient immediately after the administration of 18F-FDG and at the end of PET/CT imaging; i.e. about 90 minute after injection.

\section{RESULTS:}

The average dose received by the physicians and technologists per 18F-FDG $\mathrm{PET} / \mathrm{CT}$ procedure is given in table 1.

Table 1: Mean Average dose for Physician and Technologist

\begin{tabular}{|c|c|c|}
\hline & Physician & Technologist \\
\hline Average dose received per injection $(\mu \mathrm{Sv})$ & 4.00 & 4.75 \\
\hline Average dose received per MBq $(\mathrm{nSv})$ & 9.8 & 11.80 \\
\hline Fractional Dose Received & $46.5 \%$ & $53.5 \%$ \\
\hline
\end{tabular}

The average dose to the chest and wrist of the physicians per procedure were $3.26 \pm 0.06 \mu \mathrm{Sv}$ and $7.22 \pm 0.16 \mu \mathrm{Sv}$ respectively and similarly the average dose to the chest and wrist of the technologists per procedure were $0.46 \pm 0.06 \mu \mathrm{Sv}$ and $7.0 \pm 0.05 \mu \mathrm{Sv}$ respectively; table 2 . 
Table 2: Average Dose for Staff at Chest and Wrist.

\begin{tabular}{|c|c|c|c|c|}
\hline Worker & Chest Level & Wrist Level & Chest Level & Wrist Level \\
\cline { 2 - 5 } & $\begin{array}{c}\text { Dose/procedure } \\
\mu S v\end{array}$ & $\begin{array}{c}\text { Dose/ } \\
\text { Procedure } \mu S v\end{array}$ & $\begin{array}{c}\text { Dose/1 mCi } \\
\mu S v\end{array}$ & $\begin{array}{c}\text { Dose/1 mCi } \\
\mu S v\end{array}$ \\
\hline Physician 1 & $4.11 \pm 0.02(\mathrm{n}=68)$ & $9.82 \pm 0.12$ & 0.40 & 1.00 \\
\hline Physician 2 & $3.26 \pm 0.08(\mathrm{n}=57)$ & $10.36 \pm 0.25$ & 0.40 & 1.05 \\
\hline Technologist 1 & $4.59 \pm 0.04(\mathrm{n}=63)$ & $7.22 \pm 0.07$ & 0.45 & 0.70 \\
\hline Technologist 2 & $4.64 \pm 0.09(\mathrm{n}=62)$ & $7.36 \pm 0.05$ & 0.46 & 0.70 \\
\hline
\end{tabular}

The instantaneous dose rates were measured at different distances from the injected patients, immediately after 18F-FDG injections and at the end of PET/CT imaging. The exposure rates immediately technologists respectively. after $370 \mathrm{MBq}$ (10 $\mathrm{mCi}) 18 \mathrm{~F}-\mathrm{FDG}$ were very high at close contact $0.8 \pm 0.3$ and $0.3 \pm 0.2$ versus $0.02 \pm 0.005$ and $0.06 \pm 0.003$ at $200 \mathrm{~cm}$ for both physicians and So; each physician could inject up to 20 patients and each technologist could position up to 25 patients per day respectively; which are both out of the capacity of any department

(Table 3)

Table 3: Dose Rate at Different Distances for Physicians and Technologists:

\begin{tabular}{|l|c|c|}
\hline \multicolumn{1}{|c|}{ Dose Rate $(\mathrm{mSv} / \mathrm{h})$} & $\underline{\text { Physicians }}$ & $\underline{\text { Technologists }}$ \\
\hline Average dose received at $0 \mathrm{~cm}$ & $0.8 \pm 0.3$ & $0.3 \pm 0.2$ \\
\hline Average dose received at $50 \mathrm{~cm}$ & $0.13 \pm 0.03$ & $0.4 \pm 0.1$ \\
\hline Average dose received at $100 \mathrm{~cm}$ & $0.04 \pm 0.01$ & $0.12 \pm 0.04$ \\
\hline Average dose received at $200 \mathrm{~cm}$ & $0.02 \pm 0.005$ & $0.06 \pm 0.003$ \\
\hline
\end{tabular}

\section{DISCUSSION:}

It is imperative to continually monitor the dose received by the staff to check whether they are within the prescribed annual dose limits and also to improve the work practice for containing the radiation exposure. The critical groups that get exposure from a radioactive patient in a PET facility are the physicians and technologists performing the injection and scanning respectively ${ }^{(12)}$. In this pilot study we have estimated the dose to the physicians and technologists per PET/CT procedure.
There are few studies available in the literature comparing the dose received by the staff in conventional nuclear medicine and PET imaging. The average whole body dose per procedure to the staff in conventional nuclear medicine has been reported to be lower than that in PET facility .This is understandable due to penetrating annihilation photons and higher exposure rate constant for positron emitting radiopharmaceuticals ${ }^{(4)}$. 
Our estimated values of exposure to the staff are comparable with those published in the literature (13-15). The average dose received by the physicians administering the activity at the chest level was $4 \mu \mathrm{Sv}$ per procedure which is nearly two times higher than any conventional nuclear medicine procedure.

The radiation dose as estimated to the chest (whole body dose) and wrist; for the two physicians and two technologists are in agreement with that measured by Egyptian Authority of Atomic Energy (EAAE).

Although; our study showed higher wrist dose for the two physicians; However if they continue to work the whole year with the same workload their wrist dose would be less than $15 \mathrm{mSv}$ against the annual limit of $500 \mathrm{mSv}$. Whereas the whole body dose of all the staff was nearly same as in conventional nuclear medicine procedures. Similar and comparable results are seen in other PET facilities (16).

\section{REFRENCES:}

1. Townsend DW, Carney JPJ, Yap JT, et al. PET/CT today and tomorrow. J Nucl Med.; 45:S4-13. 2004.

2. Lundberg, T. M., Gray, P. J., Bartlett, M. L. Measuring and minimizing the radiation dose to nuclear medicine technologists. J Nucl Med Technol 30: 25-30, 2002.

3. Dell MA. Radiation safety review for $511-\mathrm{keV}$ emitters in nuclear medicine. J Nucl Med Technol.; 25:12-7. [PubMed]. 1997.

4. Roberts, F. O. Radiation dose to PET technologists and strategies to lower occupational exposure. J Nucl Med Technol 33: 44-47, 2005.
The principles of time; distance and shielding (TDS) should be practiced for any procedure involving radioactive administration, So good work practice and use of shielding devices may further reduce exposure to staff.

Particular care needs to be taken while working with the PET radiopharmaceuticals.

Depending upon the workload physicians can be put on rotation to minimize their wrist dose. Alternatively, the wrist dose could be reduced by using a $511-\mathrm{KeV}$ syringe shield ${ }^{(17)}$.

\section{CONCLUSION:}

The staff should work without any anxiety and fear of radiation risk using a PET CT facility if safe working conditions are maintained as each physician could inject up to 20 patients and each technologist could position up to 25 patients per day respectively.

5. Clarke EA, Thomson WH, Notghi A, Harding LK. Radiation doses from nuclear medicine patients to an imaging technologist: relation to ICRP recommendations for pregnant workers. Nucl Med Commun 13:795798, 1992.

6. Harbottle, E. A., Parker, R. P., Davis, R. Radiation doses to staff in a department of nuclear medicine. $\mathrm{Br} \mathrm{J}$ Radiol 49: 612-617, 1976.

7. Smart, R. Task-specific monitoring of nuclear medicine technologists' radiation exposure. Radiat Prot Dosimetry 109: 201- 209, 2004.

8. Lindner, O., Busch, F., Burchert, W. Performance of a device to minimise 
radiation dose to the hands during radioactive syringe calibration. Eur $\mathrm{J}$ Nucl Med Mol Imaging 30: 819-825, 2003.

9. Williams, E. D., Laird, E. E., Forster, E. Monitoring radiation dose to the hands in nuclear medicine: location of dosimeters. Nucl Med Commun 8: 499-503, 1987.

10. Wu, T. H. Radiation exposure during transmission measurements: comparison between CT- and germanium-based techniques with a current PET scanner. Eur J Nucl Med Mol Imaging 31: 38-43, 2004.

11. Chiesa C, De Sanctis V, Crippa F, et al. Radiation dose to technicians per nuclear medicine procedure: comparison between technetium- $99 \mathrm{~m}$, gallium-67, and iodine-131 radiotracers and fluorine-18 fluorodeoxyglucose. Eur J Nucl Med 24:1380-1389, 1997.

12. Mountford PJ, O'Doherty MJ. Exposure of critical groups to nuclear medicine patients. Appl Radiat Isotop 50: 89-111, 1999.
13. Brix $\mathbf{G}$, Lechel $\mathbf{U}$, Glatting $\mathbf{G}$, et al. Radiation exposure of patients undergoing whole-body dual-modality 18F-FDG PET/CT examinations. J Nucl Med 46: 608-613, 2005.

14. Robinson, C. N., Young, J. G., Wallace, A. B., Ibboton, V. J. A study of the personal radiation dose received by nuclear medicine technologists working in a dedicated PET center. Health Phys 88:S17-21, 2005.

15. Benatar, N. A., Cronin, B. F., O'Doherty, M. J. Radiatn dose rates from patients undergoing PET: implications for technologists and waiting areas. Eur J Nucl Med 27: 583589, 2000.

16. Pant GS, Senthamizhchelvan S. Radiation Exosure to the Staff in PET CT facility. IJNM 21: 100-103, 2006.

17. Harding, L. K., Hesslewood, S., Ghose, S. K., ThomsonW. H. The value of syringe shields in a nuclear medicine department. Nucl Med Commun 6: 449-454, 1985. 